\title{
Obesity services planning framework for interprofessional primary care organizations
}

\author{
Paula Brauer ${ }^{1}$, Dawna Royall ${ }^{2}$, John Dwyer ${ }^{1}$, A. Michelle Edwards ${ }^{1, a}$, Tracy Hussey ${ }^{3, b}$, Nick Kates ${ }^{3, c}$, \\ Heidi Smith $^{4, d}$ and Ross Kirkconnell ${ }^{5}$ \\ ${ }^{1}$ Associate Professor, Department of Family Relations and Applied Nutrition, University of Guelph, Guelph, ON, Canada \\ ${ }^{2}$ Research Coordinator, Department of Family Relations and Applied Nutrition, University of Guelph, Guelph, ON, Canada \\ ${ }^{3}$ Hamilton Family Health Team, Hamilton, Canada \\ ${ }^{4}$ Guelph Family Health Team, Guelph, Canada \\ ${ }^{5}$ Executive Director, Guelph Family Health Team, Guelph, Canada
}

\begin{abstract}
Aim: We report on a formative project to develop an organization-level planning framework for obesity prevention and management services. Background: It is common when developing new services to first develop a logic model outlining expected outcomes and key processes. This can be onerous for single primary care organizations, especially for complex conditions like obesity. Methods: The initial draft was developed by the research team, based on results from provider and patient focus groups in one large Family Health Team (FHT) in Ontario. This draft was reviewed and activities prioritized by $20 \mathrm{FHTs}$ using a moderated electronic consensus process. A national panel then reviewed the draft. Findings: Providers identified five main target groups: pregnancy to $2,3-12,13-18$, $18+$ years at health risk, and 18+ with complex care needs. Desired outcomes were identified and activities were prioritized under categories: raising awareness (eg, providing information and resources on weight-health), identification and initial management (eg, wellness care), follow-up management (eg, group programs), expanded services (eg, availability of team services), and practice initiatives (eg, interprofessional education). Overall, there was strong support for raising awareness by providing information on the weight-health connection and on community services. There was also strong support for growth assessment in pediatric care. In adults, there was strong support for wellness care/ health check visits and episodic care to identify people for interventions, for group programs, and for additional provider education. Conclusions: Joint development by different teams proved useful for consensus on outcomes and for ensuring relevancy across practices. While priorities will vary depending on local context, the basic descriptions of care processes were endorsed by reviewers. Key next steps are to trial the use of the framework and for further implementation studies to find optimally effective approaches for obesity prevention and management across the lifespan.
\end{abstract}

Key words: delivery of health care; health behavior; overweight; patient care management; primary health care

Received 2 May 2016; revised 31 August 2016; accepted 7 September 2016; first published online 3 October 2016

Correspondence to: Paula Brauer, PhD, RD, Department of Family Relations and Applied Nutrition, University of Guelph, 50 Stone Rd. E, Guelph, ON, Canada N1G 2W1. Email: pbrauer@uoguelph.ca; phcnutr@uoguelph.ca

${ }^{a}$ Present address: Data Librarian and Academic Director of the Research Data Centre, University of Guelph, Guelph, ON, Canada.

${ }^{\mathrm{b}}$ Present address: Executive Director at Farm and Food Care Ontario, 100 Stone Rd W Suite 202, Guelph, ON N1G 5L3, Canada.

${ }^{\mathrm{c}}$ Present address: Chair and Professor, Psychiatry and Behavioural Neurosciences, McMaster University.

${ }^{\mathrm{d}}$ Present address: Consulting Dietitian, Health and Performance Centre, University of Guelph, Guelph, ON, Canada.

(C) Cambridge University Press 2016 


\section{Background}

In Canada, the majority of health care is provided by primary care physicians or under their direction, with long-term person-centered care being a core value. Development of team-based care has been a stated government priority, and primary care reform is ongoing. About $81 \%$ of Canadian physicians now work in group practices and $54 \%$ have an office nurse according to a recent international survey, but it is very challenging to study primary care in Canada because most practices operate as small businesses (Wong et al., 2015). In Ontario, the first Family Health Teams (FHTs) were established in 2005 and currently 184 teams are in operation [Ministry of Health and Long-Term Care (MOHLTC), 2014]. Teams vary based on local needs, but generally consist of family physicians, nurse practitioners, nurses, dietitians, pharmacists and social workers, all regulated health professions in Canada. While the main focus remains disease-related care, prevention services are a core mandate. Co-location of team members (where possible) is a main feature as is implementation of electronic medical records systems.

Obesity is an important contributor to disease in the population, and primary care has been challenged to know how to best address the issue (Australian Primary Care Research Institute, 2012). The majority of Canadian adults and many children now carry excess body weight, part of a worldwide phenomenon (Lim et al., 2012). According to the Canadian Health Measures Survey (2009-2011), based on measured weight and height, $26.1 \%$ of adults $18-79$ years old and $11.4 \%$ of children 6-17 years old (Centers for Disease Control (CDC) standards) were considered obese and a further $34.2 \%$ of adults and $14.1 \%$ children were overweight (Statistics Canada, 2012), based on body mass index $\left[\mathrm{BMI}=\right.$ weight $(\mathrm{kg}) /$ height $\left.(\mathrm{m})^{2}\right]$.

There has been a significant gap between recommendations, and treatment and prevention services in Canada. At the beginning of this project in 2010, comprehensive obesity management practice guidelines had already been published several years earlier (Lau et al., 2007). These guidelines, developed by Obesity Canada, were comprehensive and strongly emphasized the importance of lifespan- and team-based care with a chronic disease management approach. A survey published in 2014 indicated there are few specialized programs in the country (Rosa Fortin et al., 2014). Data in primary care has been even more limited, with the electronic medical record data from the Canadian Primary Care Sentinel Surveillance Network (CPCSSN) $(n=216075)$ being the best available. According to this information, only $42 \%$ of adult patients even had a current weight recorded in 2009-2011 (Rigobon et al., 2015).

New and expanded services are going to be needed in primary care, based on the recent recommendations of the Canadian Task Force on Preventive Health Care (CTFPHC), which was re-established in 2010 to provide evidence-based guidance (using the GRADE system) on recommended prevention services to primary care (CTFPHC, 2016). Obesity prevention and treatment practice guidelines were released in 2015 and confirmed the importance of assessing growth and BMI in children and adults; and provided a strong recommendation for structured behavioral interventions to prevent diabetes in adults at risk (Brauer et al., 2015; CTFPHC, 2015).

Service planning for obesity prevention and treatment in primary care is a particular challenge for many reasons, including the need to provide services for all age groups, potential for harms, differing perspectives of multiple providers, and resource limitations. Good planning is needed to ensure services are based on current evidence, are effective and efficient, with potential for adjustment as the evidence base evolves. Among approaches to service planning, logic models are intended to clarify the links from evidence and practice to strategies and activities through to outcomes and intended effects (Program Performance and Evaluation Office, 2014). A logic model is a 'diagrammatic description of a program by depicting its goals and objectives, the component activities needed to accomplish the goals, their outputs (countable by-products of each component), short and long-term outcomes (direct results or accomplishments). It is a clear, concise tool for communicating with others about the program.' (Woodward, 2010: 1). Methods for developing logic models have generally been based on some sort of group process, but vary widely. Group development of an initial logic model for primary care would help identify core and discretionary activities across different 
organizations, clarify service outcomes, and could generate new ideas for improving services. The model could be helpful to service planners within organizations who would have a base model to adapt to local circumstances (Smith et al., 2010; McKinney et al., 2013).

Formative development of such a logic model in Ontario FHTs was therefore undertaken as a series of consensus and review processes by a group of researchers and practitioners in FHTs with an interest in obesity. Three authors had been involved in a large provincial inter-disciplinary committee to more broadly introduce team-based primary care (ie, FHTs) to Ontario. The idea for developing a logic model for this topic came out of discussions at those meetings. Other co-authors were brought into help with various aspects of the projects. The overall objective was to develop an organization-level planning framework for obesity prevention and management services in interprofessional primary care settings.

\section{Methods}

\section{Overall development process}

The concept of a planning framework was more familiar to most participants than 'logic model' and therefore became the focus of discussion. The overall process of developing the planning framework is shown in Figure 1. A preliminary draft was developed by the research team based on a focus group study with patients and providers in one city-wide FHT (150 physicians) (Royall et al., forthcoming). The draft was reviewed and further developed in a pilot consensus process meeting by 11 providers (mixed professions) from one FHT. The next draft was reviewed by 19 other FHTs in four additional prioritization meetings held in different cities in the fall of 2011. An additional in-person half-day meeting was held with an expert group of researchers and decision makers in January 2012 to review the draft framework, using the same process and equipment used at the prioritization meetings. Finally, a national paper review of the summary results was completed by participants and interested stakeholders. The study was approved by the University of Guelph Research Ethics Board and all participants completed and signed consent forms before participating in the research.

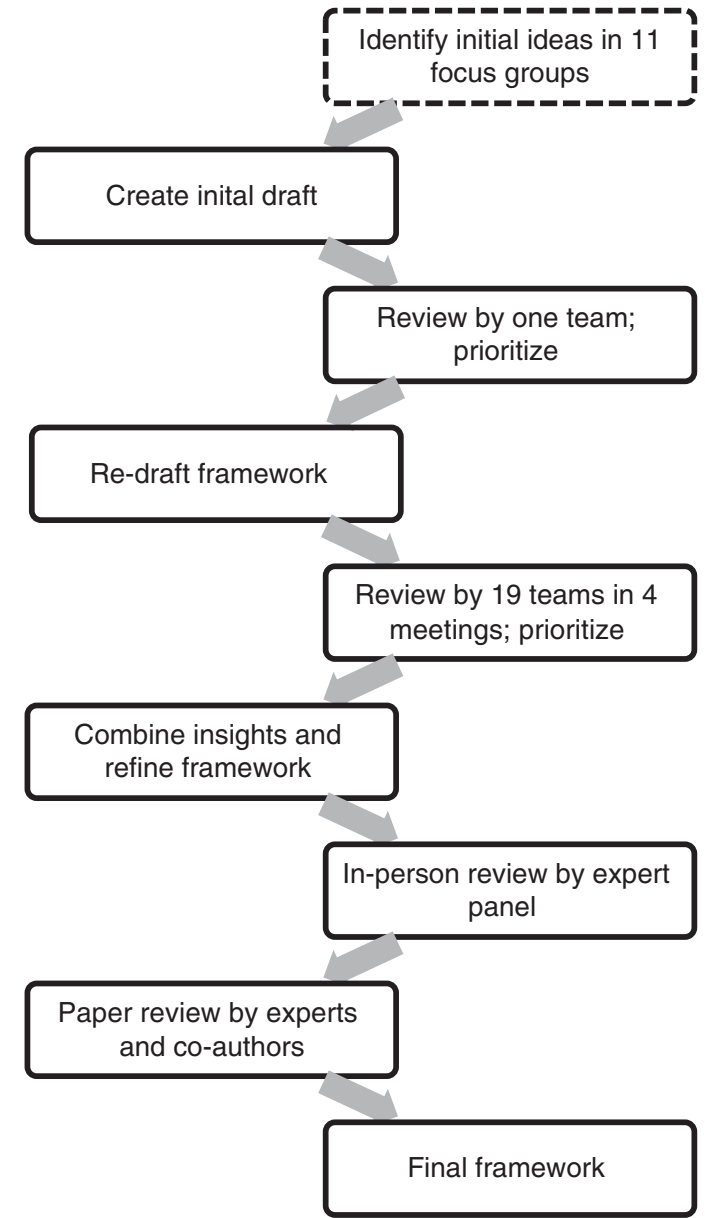

Figure 1 Overall development of the obesity services planning framework. Activities described by boxes with solid lines are described in detail in this work; the activity described by the box with dashed lines is described in detail in another published work

\section{Participants}

Family Health Teams in southern Ontario were solicited to participate by email sent to Executive Directors. The FHTs were chosen for the development work as they had strategic planning capability, interprofessional teams and some had already participated in quality improvement training through a provincial quality improvement initiative (the Quality Improvement and Innovation Partnership) (Rosser et al., 2011). Feasibility was also an issue, as funding to bring teams to in-person meetings was limited. Teams were asked 
to send at least one family physician as well as two to four other providers of their choice (eg, nurse practitioner, registered nurse, dietitian, social worker or other professional).

For the expert review, the in-person moderated meeting was planned to coincide with another initiative of the Canadian Obesity Network to develop a research proposal. Invitees to that meeting were given the option of reviewing the framework. Invitees were all members of the Canadian Obesity Network, the largest national non-governmental association focused on obesity (http://www.obesitynetwork.ca/) and represented three main groups: obesity research experts, provincial decision makers and primary care researchers.

\section{Prioritization process: provider perspectives}

Prioritization meetings were conducted in one full day using a similar process. Each meeting began with an overview of the project and a draft version of the planning framework to orient participants to the work. A focus on program planning rather than specific diseases was emphasized. A mixture of nominal group and ranking exercises were conducted using linked laptops and proprietary planning software, using an external moderator from the Queens Executive Decision Centre (2013). The planning software allowed each participant to efficiently enter their ideas into a laptop computer, which could then be anonymously compiled with other participants' ideas and projected onto a screen for group discussion. The moderator trained each group on the features of the technology. Most participants were already offering obesity group programs and/or individual counseling in their FHTs. After introductions, life-stage groupings of patients were first discussed and voted on. Next, desired outcomes were considered. Participants then brainstormed strategies and interventions to address obesity for each life-stage target group; meanings were discussed, similar ideas were merged and then priorities were developed and ranked. Not all target groups could be considered at every meeting. All ideas and ranking results were tabulated and transcripts of the meeting results were produced after each meeting. The transcripts listed all of the options that had been developed in group discussion as well as the rankings. The project coordinator took notes of additional comments from the discussions.

Participants were asked to do a brief participation evaluation questionnaire at the end of the meeting, which took about $5 \mathrm{~min}$ to complete (Dehar et al., 1993). This consisted of 11 questions on a seven-point Likert-type scale related to: usefulness of the overall process undertaken during the meeting, perceived effectiveness of the planning framework developed during the meeting, and satisfaction with their contributions to the process, their own professional development and use of their time. Four additional open-ended questions obtained views on what worked well and what could be done better or differently for future meetings.

Participants in each of the meetings were sent the reports of the meetings for their own use within one month of the session they attended. Provider priorities for specific types of activities were ranked in each of the four meetings and collated after the meetings, based on the transcripts.

\section{Expert review}

In the expert review meeting, the framework was first presented and the discussion was opened up for commentary. The professional moderator reviewed the framework in the same order as in the prioritization meetings and the project coordinator took notes of the comments. The moderator sought suggestions at the end of each discussion on how the framework might be adapted and used by primary care organizations. Each participant was later sent a revised version by email for any further comments.

\section{Final development}

The framework was revised at each stage based on review of transcripts. The transcript data were content analysed for activities and strategies by two analysts using concepts and terminology expressed by participants as much as possible, based on the categories previously developed (Royall et al., forthcoming). In the prioritization meetings, overall categories emerged as themes developed from discussion of specific activities. Multiple strategies arose for each of the major categories in the process of care. These were categorized by ranking across all groups as $\mathrm{H}=$ high priority (rank 1-5), 
$\mathrm{M}=$ moderate priority (6-10) and $\mathrm{L}=$ limited priority $(>10)$, or not mentioned by providers. A basic left to right model outlining strategies was drawn using DoView software (http://doview.com/).

\section{Results}

\section{Participants and satisfaction with development process}

In the first meeting, 11 members from one FHT attended, including two family physicians. There were 78 participants (including 22 registered nurses, 22 dietitians, 16 family physicians, seven social workers, five nurse practitioners, four kinesiologists, one health promoter and one administrator), representing 19 FHTs who attended the four additional prioritization meetings. An additional 15 researchers and clinicians and three decision makers from provincial government departments participated in the expert meeting.

The process evaluation questionnaire was completed by 73 participants (94\% response) at the four meetings. Of the 11 questions regarding process, effectiveness and satisfaction with the meeting, the overall average was 6 out of 7 on a Likert-type scale (where 7 = very satisfied). In the open-ended questions, participants commented that the meeting was well facilitated, and that the electronic meeting system was an effective way to share ideas and obtain consensus. Some comments indicated that the full-day meeting was lengthy and that some of the target groups discussed were not relevant to all health care providers or FHTs. Concern was expressed that implementation of the strategies could be a challenge without additional funding or buy-in from the teams.

\section{Defining target groups}

In primary care practice, patients most often attend office visits to receive care. These visits are typically $10-15$ min long. This means providers often see people of all ages for different issues all day long. Therefore, the first task at the meeting was to define the target groups for obesity services. Participants were asked to consider 'target groups' from a program planning perspective. Accordingly, commonly associated conditions, life course stage, physical activity, prevention/treatment, provider, practice routines and the Edmonton
Obesity Staging System (Padwal et al., 2011) were all discussed. Table 1 shows examples of the dimensions considered. The goal was to create a minimum number of groupings, consistent with typical practice routines and the planning goal. The initial draft included 10 groups; after voting, five groups emerged in the first meeting, based on life course stage and disease complexity. Participants explicitly stated that prevention and treatment needed to be considered together, consistent with primary care's routines and whole person care orientation. The groups were confirmed in subsequent meetings, with some discussion of differing ways of categorizing children ( $0-5$ years) or elder (additional group) care services.

Primary care for weight issues in pregnancy and early infancy was felt to require a specific programming focus, as primary care of the mother and child unit usually occurs together and services are often offered in conjunction with other community/public health programs. In Ontario, for example, a well-baby check-up is mandated at 18 months. Determining which child ages should be considered together was a challenge for providers and ages 3-12 were put together, partly based on the organization of the Canadian school system, even though weight issues in a 3-year old would be clinically managed very differently than weight issues in a 12-year old. Teens were considered to be a separate group, with their own unique needs. The ages chosen reflected school categorizations to the completion of high school. Among adults, substantial discussion occurred regarding categorization by age and care complexity, but not by gender. In general, the majority of adults could be managed with typical office routines, while there was general agreement for the existence of a medically complex subgroup, which consumed significant time and resources, and often had health, socio-economic and other issues. Interestingly providers felt that socio-economic and mental health issues had to be considered across all life course groups, and they preferred that these issues be integrated into all services, rather than be considered as a separate grouping.

\section{Defining health outcomes by group}

The discussion to define the expected outcomes of obesity services was particularly challenging, given the diverse health issues of typical patients 
Table 1 Target groups, related health conditions, and life course issues

\begin{tabular}{|c|c|c|c|c|c|}
\hline Target group & Pregnancy to 2 years & $3-12$ years & $13-18$ years & 18+ Typical & 18+ Medically complex \\
\hline $\begin{array}{l}\text { Obesity-related health } \\
\text { conditions }\end{array}$ & $\begin{array}{l}\text { - GDM } \\
\text { - GDM - diabetes risk } \\
\text { after birth } \\
\text { - Key target group for } \\
\text { prevention }\end{array}$ & $\begin{array}{l}\text { Excess weight gain } \\
\text { for height } \\
\text { CVD risk factors } \\
\text { - Key target group for } \\
\text { prevention }\end{array}$ & $\begin{array}{l}\text { - Eating disorders } \\
\text { - CVD risk factors } \\
\text { - Mental health issues } \\
\text { affecting weight }\end{array}$ & $\begin{array}{l}\text { - Type } 2 \text { diabetes } \\
\text { - Cardiometabolic } \\
\text { syndrome } \\
\text { - CVD risk factors } \\
\text { - Mental health issues } \\
\text { affecting weight }\end{array}$ & $\begin{array}{l}\text { - Multiple chronic } \\
\text { conditions } \\
\text { - Reduced capacity for } \\
\text { activities of daily living }\end{array}$ \\
\hline $\begin{array}{l}\text { Physical activity able to } \\
\text { engage in: } 150 \mathrm{~min} / \mathrm{per} \\
\text { week (adults); } 60 \mathrm{~min} / \\
\text { day (children); moderate } \\
\text { activity (running, fast } \\
\text { walking) }\end{array}$ & $\begin{array}{l}\text { - Varies } \\
\text { - (Not applicable to } \\
\text { infants) }\end{array}$ & $\begin{array}{l}\text { - Yes mostly } \\
\text { - May have health } \\
\text { condition limiting } \\
\text { activity }\end{array}$ & $\begin{array}{l}\text { - Yes mostly } \\
\text { - May be limited }\end{array}$ & - Varies & - No \\
\hline $\begin{array}{l}\text { Relevant life course } \\
\text { issues }\end{array}$ & $\begin{array}{l}\text { - Weight gain during } \\
\text { pregnancy } \\
\text { - Retained weight } \\
\text { gain infants } \\
\text { - Growth and } \\
\text { development }\end{array}$ & $\begin{array}{l}\text { - Problems with } \\
\text { moving, running } \\
\text { - Growth and } \\
\text { development }\end{array}$ & $\begin{array}{l}\text { - Low self-esteem } \\
\text { - Growth and } \\
\text { maturation }\end{array}$ & $\begin{array}{l}\text {-Work-related } \\
\text { - Establishing families }\end{array}$ & $\begin{array}{l}\text { - Declining activities of } \\
\text { daily living }\end{array}$ \\
\hline $\begin{array}{l}\text { Edmonton Obesity } \\
\text { Staging System }\end{array}$ & Not applicable & Not applicable & Not applicable & $0-4$ & $2-4$ \\
\hline
\end{tabular}

a Edmonton Obesity Staging System Descriptions (Padwal et al., 2011): 0 - No apparent risk factors (eg, blood pressure, serum lipid and fasting glucose levels within normal range), physical symptoms, psychopathology, functional limitations and/or impairment of well-being related to obesity; 1 - Presence of obesity-related subclinical risk factors (eg, borderline hypertension, impaired fasting glucose levels, elevated levels of liver enzymes), mild physical symptoms (eg, dyspnea on moderate exertion, occasional aches and pains, fatigue), mild psychopathology, mild functional limitations and/or mild impairment of well-being; 2 - Presence of established obesity-related chronic disease (eg, hypertension, type 2 diabetes, sleep apnea, osteoarthritis), moderate limitations in activities of daily living and/or well-being; 3 - Established end-organ damage such as myocardial infarction, heart failure, stroke, significant psychopathology, significant functional limitations and/or impairment of well-being; 4 - Severe (potentially end-stage) disabilities from obesity-related chronic diseases, severe disabling psychopathology, severe functional limitations and/or severe impairment of well-being.

$\mathrm{GDM}=$ gestational diabetes mellitus; CVD = cardiovascular diseases. 
Table 2 Summary of desired health outcomes according to target group

\begin{tabular}{|c|c|c|}
\hline Target group & Desired outcomes & \\
\hline $\begin{array}{l}\text { Pregnancy to } 2 \\
\text { years }\end{array}$ & $\begin{array}{l}\text { - Preconception health } \\
\text { - Appropriate weight gain } \\
\text { - Maintaining/increasing physical activity } \\
\text { - Healthy postnatal weight loss }\end{array}$ & $\begin{array}{l}\text { - Active play } \\
\text { - Family healthy eating } \\
\text { - Infant - appropriate growth trajectory }\end{array}$ \\
\hline $3-12$ years & $\begin{array}{l}\text { - Develop healthy habits } \\
\text { - Develop parental awareness of healthy } \\
\text { lifestyles; good role modeling }\end{array}$ & $\begin{array}{l}\text { - Physically active } \\
\text { - Family-focused approach } \\
\text { - Healthy body image }\end{array}$ \\
\hline $13-18$ years & $\begin{array}{l}\text { Same as 3-12 years plus: } \\
\text { - Balance of academics and healthy lifestyle }\end{array}$ & $\begin{array}{l}\text { - Knowledge of food budgeting and meal } \\
\text { preparation } \\
\text { - Recognition and early intervention of disordered } \\
\text { eating patterns }\end{array}$ \\
\hline $18+$ years Typical & $\begin{array}{l}\text { - Weight loss or weight gain prevention } \\
\text { - increase physical activity } \\
\text { - Self-management skills for disease }\end{array}$ & $\begin{array}{l}\text { - Awareness of healthy weights/body acceptance } \\
\text { - Improved lifestyle balance } \\
\text { - Chronic disease prevention/health promotion } \\
\text { - Increased feelings of empowerment/confidence }\end{array}$ \\
\hline $\begin{array}{l}\text { 18+ years } \\
\text { Medically } \\
\text { complex }\end{array}$ & $\begin{array}{l}\text { - Achieving desired targets for chronic } \\
\text { condition } \\
\text { - Self-management skills } \\
\text { - weight maintenance/prevention of gain } \\
\text { - Improved mental health }\end{array}$ & $\begin{array}{l}\text { - Quality of life/functional capacity } \\
\text { - Prevent or reduce risk of further complications } \\
\text { - Improve mobility, physical endurance/stamina; } \\
\text { increase physical activity if able } \\
\text { - Avoid unintentional weight loss }\end{array}$ \\
\hline
\end{tabular}

and the past experiences of providers who had already been offering lifestyle services in FHTs. Providers discussed the unrealistic ideal body images in the media, the roles of other sectors, the judgment of some of their colleagues, the need for services promoting life balance rather than numbers on a scale, and the unrealistic expectations or hopes of patients regarding reasonable weight loss. The discussion emphasized the need for all providers to be realistic in their advice and expectations. Knowledge and skills goals that would be the focus of programs (eg, knowledge of when to add solids to an infant's diet or how to shop) were removed from the final health outcomes listed in Table 2. In expert review, the goal of achieving a weight for best health in adults was discussed, but the majority of providers felt such a goal was unrealistic for the majority of adults and this goal was not added.

\section{Care process and strategies}

The final planning framework (Figure 2 and Supplementary Figure for each target group) lists major process steps in obesity care, based on typical practice. Each category, such as Raising
Awareness, includes specific strategies that can be achieved with several activities. A detailed list of discussed activities is shown in the Supplementary Table. Each strategy needs to be completed by a provider to have impact. For example, Raising Awareness of the health aspects of obesity at different stages of life and health conditions is the category of care. Two common strategies are to provide information on the weight-health connection and to provide information on community resources. The activities can be as simple as providing a good pamphlet to a patient or a link to a web site. A list of community resources may be simple or may require periodic updating, depending on the practice location.

Identification and Initial Management could be within a typical episodic care visit with a physician or nurse practitioner, or could occur as part of a health check or wellness visit. Drop-in clinics were another strategy, while home visits were only considered for the medically complex and were seen as low priority and hence were omitted from the final version. Follow-up Management included various group classes and programs and different ways of providing ongoing support by the practice providers, while social and peer support 


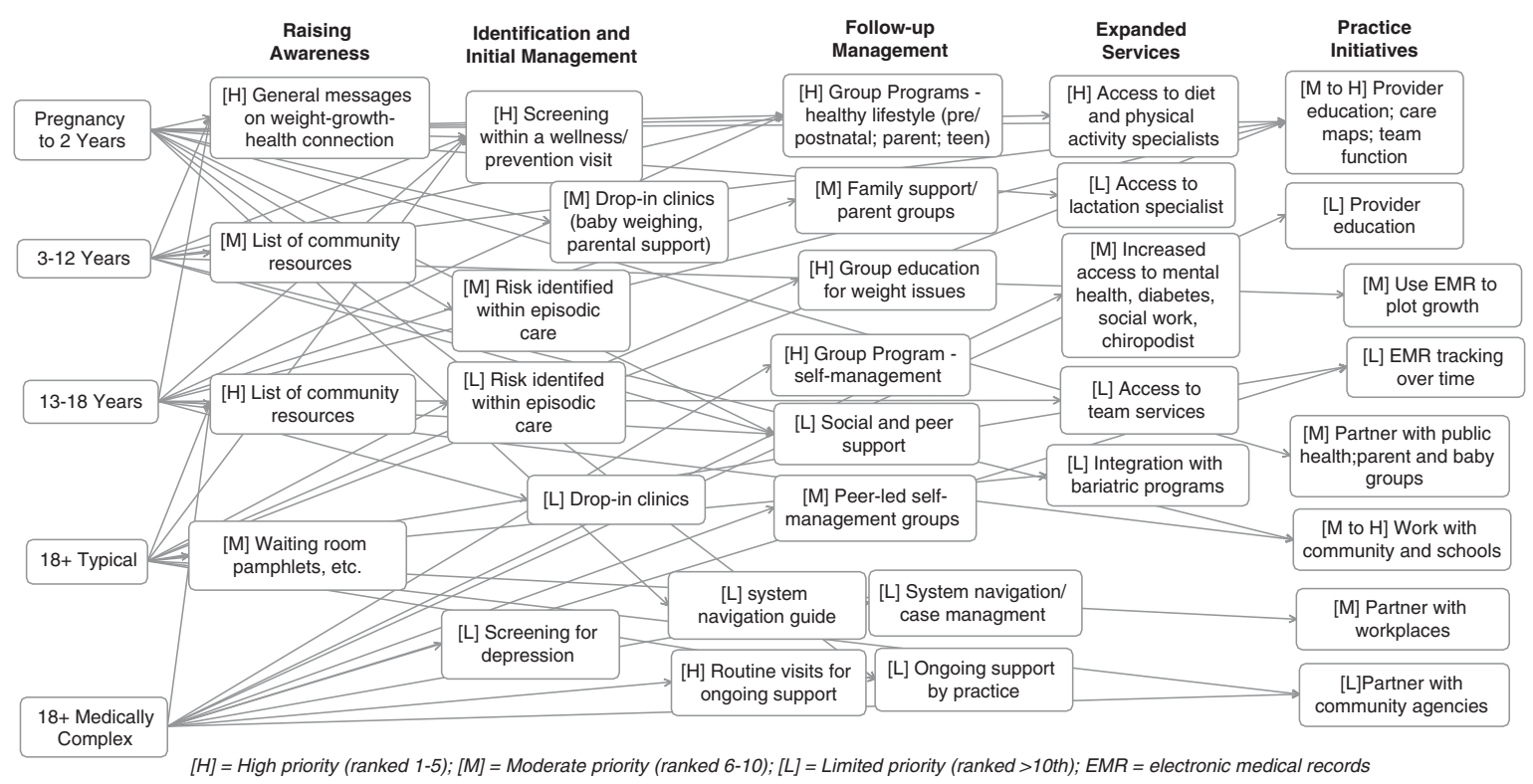

Figure 2 Overview of final planning framework. Lists the major process steps in obesity care for all target groups, based on typical practice

represented a distinct strategy, such as using the Stanford Self-Management program as a model (Lorig et al., 2012). Expanded Services included adding new expertise to the team, while access to external specialist services would be another strategy in some locations. Provider education, creation of community partnerships and outcomes review were all considered as Practice Initiatives to improve services. Features of good clinical care, such as establishing a good relationship with patients, or making sure goals are SMART (specific, measurable, attainable, realistic and time-limited) and assessing readiness to make lifestyle change are core features of all clinical care and thus were removed from this organization-level framework, not because they are not important, but because they would apply to all clinical care.

\section{Priorities of providers}

When provider priorities for specific types of activities in each of the four workshops were ranked and collated, there was broad agreement on the priorities across all groups (Figure 2). For example, a top ranked priority in one meeting would invariably be among the top five activities in the other meetings, allowing for some differences in wording. Considering providers' top ranked $(\mathrm{H})$ priorities for development first, across all groups, Figure 2 indicates that raising awareness of the weight-health connection was considered important in the three younger target groups, and providing information on community programs was prioritized among the older three groups. Presumably it would also be important for the pregnancy to 2 years group, but was not mentioned by providers.

Under Identification and Initial Management, there was general agreement that screening and initial discussion would be best managed as part of a wellness/health check visit, except among the Medically Complex, who were often being seen routinely for their chronic conditions. Obesity was considered too difficult to address within episodic care, except for the subset of the population who only interact with the primary care system for episodic care. Under Follow-Up Management, group programs were endorsed for all age groups, while only the Medically Complex merited routine follow-up and case management approaches. Thus, raising awareness by providing information on the weight-health connection and on 
community services, identification in wellness visits, and group programs were highest priority for providers.

\section{Expert review}

The meeting confirmed the life-stage groupings chosen initially. There were diverse opinions on desired outcomes, with some experts expressing the view that weight loss should have been more prominent among the desired outcomes. The naming of some of the categories of care process were also problematic and were replaced in the final framework with Initial Identification and Management, Follow-up Management and Expanded Services.

Experts also felt there was limited evidence to support many of the high priority ideas identified by providers, as each idea had been prioritized in the draft. This was revised in the final framework by combining similar specific ideas under more general priorities, and categorizing the rankings as high, moderate or low priority. Ideas generated by providers for one or two target groups did not always emerge for other groups, even where this would have been logical. This can be seen in the Supplementary Figure by target group. It was also felt that prioritization by provider perspective was novel, but incomplete, and experts wanted to know to what degree evidence aligned with provider ideas. No additional feedback was received from providers on the revised version of the framework.

\section{Discussion}

Development of this planning framework for obesity prevention and lifestyle treatment services was a first attempt to produce a framework for overall care processes needed across the age spans served by primary care. It incorporated various features that have been promoted by health system planning groups, including population-based planning (World Health Organization, 2005), teams and decision support tools (MOHLTC, 2012) with provider and patient perspectives on acceptable services [Medical Research Council (UK), 2008].

The use of such frameworks (or logic models) may be useful in primary care, especially in identifying key processes consistent with typical practice [Medical Research Council (UK), 2008;
Mitchell et al., 2008; Nemeth et al., 2008]. While there is substantial evidence for structured behavioral, pharmacological and surgical treatment of obesity, the process of developing the framework by provider groups already working in teams identified key areas for further development, including tools and strategies for raising awareness of the weight and health links, and greater use of wellness visits. There is a lack of evidence to support best practices for these priorities, as evidenced by the lack of any screening studies for adult obesity in the CTFPHC systematic review (Brauer et al., 2015). For children, the CTFPHC did identify very low quality evidence to support growth monitoring and moderate quality evidence to recommend structured behavioral interventions in primary care to promote healthy weight management in children (CTFPHC, 2015). Despite these recommendations, the evidence base for these complex interventions is confusing, as it has not been possible in meta-analyses to date to identify which elements of the most effective behavioral interventions need to be included in programs to achieve greatest effectiveness (Peirson et al., 2014). This is a problem common to most complex interventions and is an active area of current research (Hoffmann et al., 2014; Hoffmann et al., 2015). More work is needed to ensure that researchers and analysts conducting knowledge syntheses describe interventions in ways that align with how providers think about service planning. For example, research would be welcome on the value of the 'wellness visit' for obesity prevention or management, an area of controversy in family medicine.

The differences of opinion that emerged among providers and experts on the relevant health outcomes of care need further discussion and development. For example, providers' focus on providing realistic advice and expectations regarding weight loss is in contradiction to some expert opinion to achieve 'healthy weight for optimal health,' and is inconsistent with the evidence from recent systematic reviews that identifies an average mean weight loss of about $3 \mathrm{~kg}$ in adults with lifestyle programs and an additional $3 \mathrm{~kg}$ when pharmacological agents (metformin and orlistat) are used (Peirson et al., 2014; 2015). This modest level of weight loss was associated with diabetes prevention in those at risk, and led to a strong recommendation by the 
CTFPHC for lifestyle programs in primary care (Brauer et al., 2015). Over time, we expect there will be greater consensus on core messaging.

The planning framework appears to be novel, and no published examples for obesity were found in the literature. The framework clarifies some areas for new work, such as the need for studies on how best to raise awareness of the obesity issue in a health care context.

To date, most development of primary care resources has focused on tools for patients or providers to use in the direct client service context, such as variations of the 5As tool (Ask, Assess, Advise, Agree, Assist), which is currently being tested in primary care (Campbell-Scherer et al., 2014), the Craving Change curriculum for a groupbased cognitive behavioral program addressing emotional eating (Cannon and Shah, 2013) or the group-based Diabetes Prevention Programs (DPP) manuals (DPP Research Group, 2014). These tools/workshops and courses are clearly needed, but there is also a need for more service planning tools.

Some strengths of the processes used to develop the framework included guided discussion with prioritization across different disciplines, which proved invaluable in clarifying key care processes for planning purposes. Involving patients and providers early in the process of development ensured that descriptions of the care processes were consistent with typical terminology used by providers in describing care processes. The organization of the framework based on provider ways of describing services ensured that the framework would be relevant to primary care.

Use of ranking exercises revealed broad consensus on main issues that need to be addressed first in Ontario team-based primary care. Working with one model of primary care was both a strength and a limitation. Family Health Teams are a relatively new team-based model in Ontario, and most FHTs have already been involved in efforts to improve chronic disease management (MOHLTC, 2014). Participants were an interested group of providers who understand the challenges of obesity and had already implemented a range of lifestyle programs. Use of one progressive model of primary care allowed differences and similarities in perspectives across disciplines to emerge and be included in the development process.

\section{Limitations}

The framework might be less applicable to other models of team-based primary care in Canada and elsewhere; for example region-based or strictly referral-based models where specialized services like lifestyle counseling are not co-located with medical care. In addition, the mix of providers differs across models. In FHTs, dietitians, nurses and social workers were team members, but kinesiology was not a regulated health profession at the time of the study and they were not typically included among possible team members. All providers volunteered to participate in the study and the results reflect the viewpoints of participants. Another limitation of the process was that providers did not have an opportunity to consider priorities across the different target groups; each target group was considered separately. Some approaches prioritized for some age groups were not mentioned for other age groups and it is unclear if these omissions were intended or not. Additional review by others is needed to further review the prioritized strategies and to articulate the underlying assumptions (beliefs and knowledge) that support prioritization of the strategies in the FHT context first, and then more broadly in other primary care organizations. In addition, some types of evidence relevant to primary care but not obesity specifically, such as practice facilitation (Baskerville et al., 2012) or long-term tracking of results in electronic health records for planning (Wagner et al., 2001) were not mentioned by providers but have been shown to improve service effectiveness.

\section{Conclusion/next steps}

Overall, there was strong support by the teambased providers for growth assessment, including weight and height as one element of routine pediatric care. In adults, there was strong support for use of wellness care/health check visits and episodic care to identify people for interventions, for group programs, and for provider education directed to creation of care routines or maps. Clearly, there is a need for further targeted research to ensure new services will be both effective and efficient. This planning framework can be used as the basis for further service 
planning and new implementation studies. Finally, additional work is needed to develop and validate approaches to blending evidence with provider and patient perspectives to ensure planned services are both evidence-based and consistent with typical acceptable and feasible practice in the health system.

\section{Acknowledgments}

None.

\section{Financial Support}

CIHR Knowledge to Action, 200805KAL-189174KAL-CEHA-55685 and CIHR Meetings, Planning and Dissemination, KT Supplement 21010KTB238517-KTB-CEHA55685

\section{Conflicts of Interest}

None.

\section{Ethical Standards}

The authors assert that all procedures contributing to this work comply with the ethical standards of the relevant national and institutional guidelines on human experimentation from the University of Guelph and with the Helsinki Declaration of 1975, as revised in 2008.

\section{Supplementary material}

To view supplementary material for this article, please visit http://10.1017/S1463423616000372

\section{References}

Australian Primary Care Research Institute. 2012: The Centre for Obesity Management and Prevention Research Excellence in Primary Health Care. Retrieved 12 April 2016 from http:/aphcri.anu.edu.au/aphcri-network/centres-researchexcellence-cres/centre-obesity-management-and-preventionresearch.

Baskerville, N.B., Liddy, C. and Hogg, W. 2012: Systematic review and meta-analysis of practice facilitation within primary care settings. Annals of Family Medicine 10, 63-74.

Brauer, P., Connor, G.S., Shaw, E., Singh, H., Bell, N., Shane, A.R., Jaramillo, A. and Tonelli, M. 2015: Recommendations for prevention of weight gain and use of behavioural and pharmacologic interventions to manage overweight and obesity in adults in primary care. Canadian Medical Association Journal 187, 184-95.

Campbell-Scherer, D.L., Asselin, J., Osunlana, A.M., Fielding, S., Anderson, R., Rueda-Clausen, C.F., Johnson, J.A., Ogunleye, A.A., Cave, A., Manca, D. and Sharma, A.M. 2014: Implementation and evaluation of the 5As framework of obesity management in primary care: design of the $5 \mathrm{As}$ Team (5AsT) randomized control trial. Implementation Science 9, 78.

Canadian Task Force on Preventive Health Care (CTFPHC). 2015: Recommendations for growth monitoring, and prevention and management of overweight and obesity in children and youth in primary care. Canadian Medical Association Journal 187, 411-21.

Canadian Task Force on Preventive Health Care (CTFPHC). 2016: Canadian Task Force on Preventive Health Care. Retrieved 28 February 2016 from http://canadiantaskforce. $\mathrm{ca} /$ ? content $=$ pcp.

Cannon, C. and Shah, W. 2013: Craving change program. Retrieved 12 April 2016 from http://www.cravingchange.ca/.

Dehar, M.A., Casswell, S. and Duignan, P. 1993: Formative and process evaluation of health promotion and disease prevention programs. Evaluation Review 17, 204-20.

Diabetes Prevention Program (DPP) Research Group. 2014: Lifestyle Manuals of Operations. Retrieved 12 April 2016 from https://dppos.bsc.gwu.edu/web/dppos/lifestyle.

Hoffmann, T.C., Glasziou, P.P., Boutron, I., Milne, R., Perera, R., Moher, D., Altman, D.G., Barbour, V., Macdonald, H., Johnston, M., Lamb, S.E., Dixon-Woods, M., McCulloch, P., Wyatt, J.C., Chan, A.W. and Michie, S. 2014: Better reporting of interventions: template for intervention description and replication (TIDieR) checklist and guide. British Medical Journal 348, g1687.

Hoffmann, T.C., Walker, M.F., Langhorne, P., Eames, S., Thomas, E. and Glasziou, P. 2015: What's in a name? The challenge of describing interventions in systematic reviews: analysis of a random sample of reviews of nonpharmacological stroke interventions. British Medical Journal Open 5, e009051.

Lau, D.C., Douketis, J.D., Morrison, K.M., Hramiak, I.M., Sharma, A.M. and Ur, E., Obesity Canada Clinical Practice Guidelines Expert Panel. 2007: 2006 Canadian clinical practice guidelines on the management and prevention of obesity in adults and children [summary]. Canadian Medical Association Journal 176, S1-13.

Lim, S.S., Vos, T., Flaxman, A.D., Danaei, G., Shibuya, K., AdairRohani, H., Amann, M., Anderson, H.R., Andrews, K.G., Aryee, M., Atkinson, C., Bacchus, L.J., Bahalim, A.N., Balakrishnan, K., Balmes, J., Barker-Collo, S., Baxter, A., Bell, M.L., Blore, J.D., Blyth, F., Bonner, C., Borges, G., Bourne, R., Boussinesq, M., Brauer, M., Brooks, P., Bruce, N.G., Brunekreef, B., Bryan-Hancock, C., Bucello, C., Buchbinder, R., Bull, F., Burnett, R.T., Byers, T.E., Calabria, B., Carapetis, J., Carnahan, E., Chafe, Z., Charlson, F., Chen, H., Chen, J.S., Cheng, A.T., Child, J.C., 
Cohen, A., Colson, K.E., Cowie, B.C., Darby, S., Darling, S., Davis, A., Degenhardt, L., Dentener, F., Des Jarlais, D.C., Devries, K., Dherani, M., Ding, E.L., Dorsey, E.R., Driscoll, T., Edmond, K., Ali, S.E., Engell, R.E., Erwin, P.J., Fahimi, S., Falder, G., Farzadfar, F., Ferrari, A., Finucane, M.M., Flaxman, S., Fowkes, F.G., Freedman, G., Freeman, M.K., Gakidou, E., Ghosh, S., Giovannucci, E., Gmel, G., Graham, K., Grainger, R., Grant, B., Gunnell, D., Gutierrez, H.R., Hall, W., Hoek, H.W., Hogan, A., Hosgood, H.D., III, Hoy, D., Hu, H., Hubbell, B.J., Hutchings, S.J., Ibeanusi, S.E., Jacklyn, G.L., Jasrasaria, R., Jonas, J.B., Kan, H., Kanis, J.A., Kassebaum, N., Kawakami, N., Khang, Y.H., Khatibzadeh, S., Khoo, J.P., Kok, C., Laden, F., Lalloo, R., Lan, Q., Lathlean, T., Leasher, J.L., Leigh, J., Li, Y., Lin, J.K., Lipshultz, S.E., London, S., Lozano, R., Lu, Y., Mak, J., Malekzadeh, R., Mallinger, L., Marcenes, W., March, L., Marks, R., Martin, R., McGale, P., McGrath, J., Mehta, S., Mensah, G.A., Merriman, T.R., Micha, R., Michaud, C., Mishra, V., Hanafiah, K.M., Mokdad, A.A., Morawska, L., Mozaffarian, D., Murphy, T., Naghavi, M., Neal, B., Nelson, P.K., Nolla, J.M., Norman, R., Olives, C., Omer, S.B., Orchard, J., Osborne, R., Ostro, B., Page, A., Pandey, K.D., Parry, C.D., Passmore, E., Patra, J., Pearce, N., Pelizzari, P.M., Petzold, M., Phillips, M.R., Pope, D., Pope, C.A., III, Powles, J., Rao, M., Razavi, H., Rehfuess, E.A., Rehm, J.T., Ritz, B., Rivara, F.P., Roberts, T., Robinson, C., RodriguezPortales, J.A., Romieu, I., Room, R., Rosenfeld, L.C., Roy, A., Rushton, L., Salomon, J.A., Sampson, U., Sanchez-Riera, L., Sanman, E., Sapkota, A., Seedat, S., Shi, P., Shield, K., Shivakoti, R., Singh, G.M., Sleet, D.A., Smith, E., Smith, K.R., Stapelberg, N.J., Steenland, K., Stockl, H., Stovner, L.J., Straif, K., Straney, L., Thurston, G.D., Tran, J.H., Van, D.R., van, D.A., Veerman, J.L., Vijayakumar, L., Weintraub, R., Weissman, M.M., White, R.A., Whiteford, H., Wiersma, S.T., Wilkinson, J.D., Williams, H.C., Williams, W., Wilson, N., Woolf, A.D., Yip, P., Zielinski, J.M., Lopez, A.D., Murray, C.J., Ezzati, M., AlMazroa, M.A. and Memish, Z.A. 2012: A comparative risk assessment of burden of disease and injury attributable to 67 risk factors and risk factor clusters in 21 regions, 1990-2010: a systematic analysis for the Global Burden of Disease Study 2010. Lancet 380, 2224-260.

Lorig, K., Holman, H., Sobel, D., Laurent, D., Gonzalez, V. and Minor, M. 2012: Living a Healthy Life With Chronic Conditions: Self-Management of Heart Disease, Arthritis, Diabetes, Depression, Asthma, Bronchitis, Emphysema \& Other Physical \& Mental Health Conditions, fourth edition. Boulder, CO: Bull Publishing.

McKinney, L., Skolnik, N. and Chrusch, A. 2013: Diagnosis and management of obesity. Retrieved 12 April 2016 from http:// www.aafp.org/patient-care/public-health/fitness-obesity.html.

Medical Research Council (UK). 2008: Developing and evaluating complex interventions: new guidance. Retrieved 12 April 2016 from www.mrc.ac.uk/complexintervention sguidance.

Primary Health Care Research \& Development 2017; 18: 135-147
Ministry of Health and Long-Term Care (MOHLTC). 2012: Ontario's Chronic Disease Prevention and Management Framework. Retrieved 12 April 2016 from http://www. hqontario.ca/portals/0/Documents/qi/qi-oncdpm-en.pdf.

Ministry of Health and Long-Term Care (MOHLTC). 2014: Family health teams. Retrieved 12 April 2016 from http:// www.health.gov.on.ca/en/pro/programs/fht/.

Mitchell, G.K., Tieman, J.J. and Shelby-James, T.M. 2008: Multidisciplinary care planning and teamwork in primary care. Medical Journal of Australia 188, S61-64.

Nemeth, L.S., Feifer, C., Stuart, G.W. and Ornstein, S.M. 2008: Implementing change in primary care practices using electronic medical records: a conceptual framework. Implementation Science 3, 3.

Padwal, R.S., Pajewski, N.M., Allison, D.B. and Sharma, A.M. 2011: Using the Edmonton obesity staging system to predict mortality in a population-representative cohort of people with overweight and obesity. Canadian Medical Association Journal 183, E1059-1066.

Peirson, L., Douketis, J., Ciliska, D., Fitzpatrick-Lewis, D., Ali, M.U. and Raina, P. 2014: Treatment for overweight and obesity in adult populations: a systematic review and metaanalysis. Canadian Medical Association Journal Open 2, E306-317.

Peirson, L., Fitzpatrick-Lewis, D., Ciliska, D., Usman, A.M., Raina, P. and Sherifali, D. 2015: Strategies for weight maintenance in adult populations treated for overweight and obesity: a systematic review and meta-analysis. Canadian Medical Association Journal Open 3, E47-54.

Program Performance and Evaluation Office. 2014: Manuals/ assistance with specific evaluation steps - logic models. Retrieved 12 April 2016 from http://www.cdc.gov/evaL/ resources/index.htm.

Queens Executive Decision Centre. 2013: About the centre. Retrieved 12 April 2016 from https://smith.queensu.ca/ centres/decision-centre/index.php.

Rigobon, A.V., Birtwhistle, R., Khan, S., Barber, D., Biro, S., Morkem, R., Janssen, I. and Williamson, T. 2015: Adult obesity prevalence in primary care users: an exploration using Canadian Primary Care Sentinel Surveillance Network (CPCSSN) data. Canadian .Journal of Public Health 106, e283-289.

Rosa Fortin, M.M., Brown, C., Ball, G.D., Chanoine, J.P. and Langlois, M.F. 2014: Weight management in Canada: an environmental scan of health services for adults with obesity. BMC Health Services Research 14, 69.

Rosser, W.W., Colwill, J.M., Kasperski, J. and Wilson, L. 2011: Progress of Ontario's Family Health Team model: a patientcentered medical home. Annals of Family Medicine 9, 165-71.

Royall, D., Brauer, P., Atta-Konadu, E., Dwyer, J.J.M., Edwards, A.M., Hussey, T. and Kates, N. forthcoming: Eliciting provider and patient perspectives on new obesity management services in a team-based primary care organization. Canadian Journal of Dietetic Practice and Research.

Smith, P.D., O'Halloran, P., Hahn, D.L., Grasmick, M. and Radant, L. 2010: Screening for obesity: clinical tools in 
evolution, a WREN study. Wisconsin Medical Joural 109, 274-78.

Statistics Canada. 2012: Canadian Health Measures Survey: cycle 2 data tables. Retrieved 12 April 2016 from www. statcan.gc.ca.

Wagner, E.H., Austin, B.T., Davis, C., Hindmarsh, M., Schaefer, J. and Bonomi, A. 2001: Improving chronic illness care: translating evidence into action. Health Affairs (Millwood) 20, 64-78.

Wong, S.T., Chau, L.W., Hogg, W., Teare, G.F., Miedema, B., Breton, M., Aubrey-Bassler, K., Katz, A., Burge, F.,
Boivin, A., Cooke, T., Francoeur, D. and Wodchis, W.P. 2015: An international cross-sectional survey on the Quality and Costs of Primary Care (QUALICO-PC): recruitment and data collection of places delivering primary care across Canada. BMC Family Practice 16, 20.

Woodward, C. 2010: Logic model resource guide for family health teams. Retrieved 12 April 2016 from http://www.hqontario.ca/ Portals/0/documents/qi/qi-rg-logic-model-1012-en.pdf.

World Health Organization. 2005: Preventing chronic diseases: a vital investment. Retrieved 12 April 2016 from http://www. who.int/chp/chronic_disease_report/en/. 